\title{
ASRAMA MAHASISWA UNIVERSITAS MUSAMUS MERAUKE (PENERAPAN DESAIN GREEN ARCHITECTURE)
}

\author{
Yosi Valentina Simorangkir*1, Anton Topan ${ }^{2}$, Muchlis Alahudin ${ }^{3}$, Ragil Hidayat ${ }^{4}$ \\ ${ }^{1}$ Jurusan Arsitektur, Fakultas Teknik, Universitas Musamus, Merauke \\ Jl. Kamizaun Mopah Lama Merauke, Papua, 99611 \\ *Email: simorangkir@unmus.ac.id
}

\begin{abstract}
Abstrak
Asrama mahasiswa Universitas Musamus merupakan salah satu fasilitas yang disediakan oleh pihak Universitas bagi para mahasiswa, khususnya yang berasal dari luar daerah atau rumah yang jauh. Perancangan asrama mahasiswa ini dapat memberikan fasilitas yang baik demi kenyamanan bagi penghuninya dengan menerapkan unsur filosofi perancangan sarang lebah dan tema serta penerapan desain Green Architecture. Penelitian menggunakan metode deskriptis yaitu untuk mencari unsur-unsur, ciri-ciri, sifat-sifat. Metode deskriptis dilakukan melalui: survey, dokumentasi dan wawancara. Dimana data yang di peroleh akan menjadi acuan pada desain asrama. Jumlah mahasiswa UNMUS sampai tahun 2016 adalah 9000 mahasiswa, untuk penghuni asrama diambil 60\% dari jumlah mahasiswa yaitu 4.000 mahasiswa (putra-putri). Luas tapak asrama mahasiswa adalah $90.000 \mathrm{~m}^{2}(9 \mathrm{Ha})$. Penghuni asrama dengan presentase $59 \%$ putra dan $41 \%$ putri, pembagian kelas asrama yaitu terdiri kelas 1: putra (1416), putri (984), kelas 2putra (708) dan putri (492) serta kelas 3: putra (236) dan putri (164). Penerapan Green Architechture diharapkan dapat memaksimalkan sumber daya alam, antara lain: pemanfaatan air hujan, memaksimalkan pencahayaan alami (skylight), memperbesar bukaan (bukaan dapat ditembus oleh cahaya dan udara), dengan bangunan panggung, udara dapat mengalir dalam bangunan dengan baik, penataan/pola tata masa bangunan dan penanaman vegetasi diharapkan dapat menghambat kecepatan angin.
\end{abstract}

\begin{abstract}
Musamus University student dormitory is one of the facilities provided by the University for students, especially those from outside the area or distant homes. The design of this student dormitory can provide good facilities for the convenience of its occupants by applying the philosophy of honeycomb design and themes as well as the application of Green Architecture designs. Research uses descriptive method, namely to look for elements, characteristics, traits. Descriptive methods are carried out through: surveys, documentation and interviews. Where the data obtained will be a reference to the dormitory design. The number of UNMUS students until 2016 is 9,000 students, $60 \%$ of the total number of students in the dormitory is 4,000 students (boys and girls). The area of the student dormitory is $90,000 \mathrm{~m} 2$ ( $9 \mathrm{Ha}$ ). Dormitory residents with a percentage of $59 \%$ of sons and $41 \%$ of daughters, division of dormitory class which consists of class 1: sons (1416), daughters (984), class 2putra (708) and daughters (492) and class 3: sons (236) and daughters (164). The application of Green Architechture is expected to maximize natural resources, including: utilization of rainwater, maximizing natural lighting (skylights), enlarging openings (openings can be penetrated by light and air), with the building stage, air can flow in the building properly, arrangement / building design patterns and vegetation planting are expected to inhibit wind speed.
\end{abstract}

Kata Kunci:Asrama Mahasiswa.,Green Architecture., Universitas Musamus Merauke.

\section{Pendahuluan}

Di era yang serba maju dengan pesat terutama dalam bidang IPTEKS (Ilmu Pengetahuan, Teknologi dan Seni) pemerintah selalu berupaya memberikan kualitas yang terbaik untuk sumber daya manusianya terutama dalam bidang pendidikan. Selain itu juga melakukan pemerataan pendidikan diseluruh pelosok agar semua dapat mengecam pendidikan yang baik dan layak dari umur sedini mungkin hingga kejenjang perguruan tinggi.

Universitas sebagai lembaga pendidikan tertinggi bukan saja merupakan lembaga pendidikan yang hanya mengajarkan pendidikan Akademik atau formal saja, namun juga mengajarkan tentang kemasyarakatan yang merupakan kesatuan dari sistem tersendiri.

Kabupaten Merauke adalah salah satu kabupaten di Provinsi Papua. Perkembangan pendidikan di kota Merauke semakin meningkat, 
bisa di lihat dari perkembangan pembangunan gedung-gedung sekolah baik dari sekolah dasar hingga perguruan tinggi yang negeri ataupun swasta.

Peningkatan jumlah mahasiswa dan mahasiswi dari lima tahun terakhir pada tahun 2011-2016 jumlah rata-rata peningkatan setiap tahunnya $18,42 \%$ atau 1.842 mahasiswa, memaksa pihak Universitas Musamus Merauke untuk tidak hanya mengembangkan fasilitas dibidang pendidikan saja, namun juga perlu mengembangkan fasilitas penunjang lainnya yang tidak kalah pentingnya dalam usaha untuk meningkatkan kegiatan belajar-mengajar salah satunya yaitu sarana tempat tinggal berupa Asrama Mahasiswa dan Mahasiswi.

Maka perlu di rencanakan dan di rancang asrama untuk menampung mahasiswa dan mahasiswi Universitas Musamus Merauke yang diharapkan dapat memberikan solusi baru untuk kebutuhan tempat tinggal yang layak, aman dan, nyaman. Dengan demikian hasil desain diharapkan sesuai dengan kenyataan yang ada dan mampu memenuhi kebutuhan mahasiswa dalam bertempat tinggal dan menuntut ilmu dengan nyaman.

Berdasarkan latar belakang di atas perancang mengambil judul Asrama Mahasiswa Universitas Musamus Merauke dengan pendekatan Green Architechture. Green Architechture atau sering disebut sebagai Arsitektur hijau adalah arsitektur yang minim mengonsumsi sumber daya alam, termasuk energi, air, dan material, serta minim menimbulkan dampak negatif bagi lingkungan. Arsitektur hijau adalah suatu pendekatan perencanaan bangunan yang berusaha untuk meminimalisasi berbagai pengaruh membahayakan pada kesehatan manusia dan lingkungan [1]

\section{TINJAUAN PUSTAKA}

\subsection{Jenis Kegiatan}

Jenis-jenis kegiatan yang dilakukan dalam asrama adalah sebagai berikut:

1. Kegiatan pembiasaan asrama adalah kegiatan yang dilaksanakan harian sebagai pembiasaan perilaku positif bagi penghuni asrama.
2. Kegiatan rutin asrama adalah kegiatan yang dilaksanakan bulanan bagi seluruh penghuni asrama.

3. Kegiatan Life skill adalah merupakan kegiatan pengembangan dan pembentukan karakter yang dilaksanakan bulanan bagi seluruh penghuni asrama.

\subsection{Standar Bangunan Bertingkat}

Bangunan bertingkat ini dibangun berdasarkan keterbatasan tanah yang mahal di perkotaan dan tingginya tingkat permintaan ruang untuk berbagai macam kegiatan.

1. Struktur pondasi adalah elemen sistem struktur yang berfungsi menopang keseluruhan beban dan menjaga berdirinya bangunan dan meneruskannya ke dalam tanah.

2. Denah bangunan gedung dan rumah sebaiknya sederhana, simetris terhadap kedua sumbu bangunan dan tidak terlalu panjang. Perbandingan lebar bangunan dengan panjang $1: 2$.

3. Struktur bangunan adalah bagian dari sebuah system bangunan yang bekerja untuk menyalurkan beban yang di akibatkan oleh adanya bangunan di atas tanah.Fungsi struktur dapat di simpulkan untuk memberi kekuatan dan kekakuan yang di perlukan untuk mencegah sebuah bangunan mengalami keruntuhan. [2]

\subsection{Standar Persyaratan Asrama}

Adapun standar persyaratan asrama adalah:

1. Konfigurasi Ruang Tidur Asrama

2. Standar Luas Ruang Tidur

3. Fasilitas-fasilitas dalam asrama [3]

\subsection{Tinjauan Arsitektur}

Adapun beberapa tinjauan dalam arsitektur adalah:

1. Pendekatan green architecture

2. Mengenal Arsitektur Hijau

3. Ciri-ciri Arsitektur Hijau

4. Aspek pedoman dalam bangunan hijau

5. Penerapan aspek bangunan hijau

6. Manfaat pembangunan green building 
2.5 Tema dan Filosofi Perancangan

1. Tema perancangan "hive" yang berarti Lebah. Maksud dari tema perancangan ini adalah penerapan dari karakter lebah yang mempunyai sifat apik dan resik, yang di harapkan mempunyai tampilan fisik yang apik (bagus) serta memiliki jaringan utilitas yang baik sehingga menciptakan rancangan yang terlihat resik (bersih).

2. Filosofi bentuk yang di ambil dalam perancangan asrama mahasiswa adalah "bee hive"(sarang lebah). Alasan mengambil filosofi ini adalah kehebatan bentuk heksagon (segi enam) yang terdapat pada sarang lebah yang akan di terapkan pada perancangan asrama mahasiswa UNMUS.

\section{METODE PENELITIAN}

Dalam hal ini, tempat atau lokasi yang peneliti gunakan untuk perencanaan Asrama Mahasiswa berada pada Kawasan kampus Universitas Musamus Merauke yang terletak di jalan Kamizaun.

Data yang digunakan pada penelitian ini adalah data yang diperoleh dari observasi, wawancara, studi pustaka serta kuesioner yang berisikan jenis data primer dan sekunder yang beralasakan pada sumber data [4]

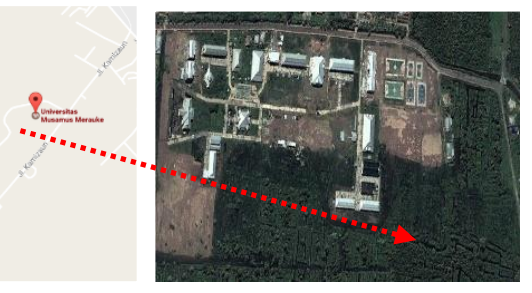

Gambar 1. Lokasi tapak

\section{HASIL DAN PEMBAHASAN}

4.1 Besaran Bangunan

Tabel 1. Kebutuhan dan besaran ruang

\begin{tabular}{ccc}
\hline No. & Kebutuhan Ruang & Luas \\
\hline 1 & Gedung Asrama Mahasiswa & 25006 \\
2 & Gedung Pengelola & 267.45 \\
3 & Gedung Penunjang & 31987 \\
\hline \multicolumn{3}{c}{ Total } \\
\hline
\end{tabular}

Analisis terhadap besaran ruang dilakukan dengan mempertimbangkan berbagai hal yang mendukung terwujudnya suatu besaran ruang yang optimal dan efektif. Dalam hal ini, penulis menentukan besaran ruang yang berdasarkan:
a. Neufert architecture data
b. Standar tata ruang
c. Time saver standar for building type
d. Asumsi

Meninjau dari perhitungan besaran ruang di atas, maka dapat disimpulkan luas gedung asrama dan open space $60 \%$,maka luas total perancangan ini adalah 9 ha.

\subsection{Lokasi Tapak}

Penentuan lokasi didasarkan pada beberapa pertimbangan berikut:

1. Pencapaian ke lokasi yang mudah dijangkau.

2. Kelengkapan utilitas kota.

3. Memiliki luas lahan yang cukup.

4. Penentuan lokasi terpilih berdasarkan kuesioner yang di isi oleh teman-teman mahasiswa Universitas Musamus Merauke.

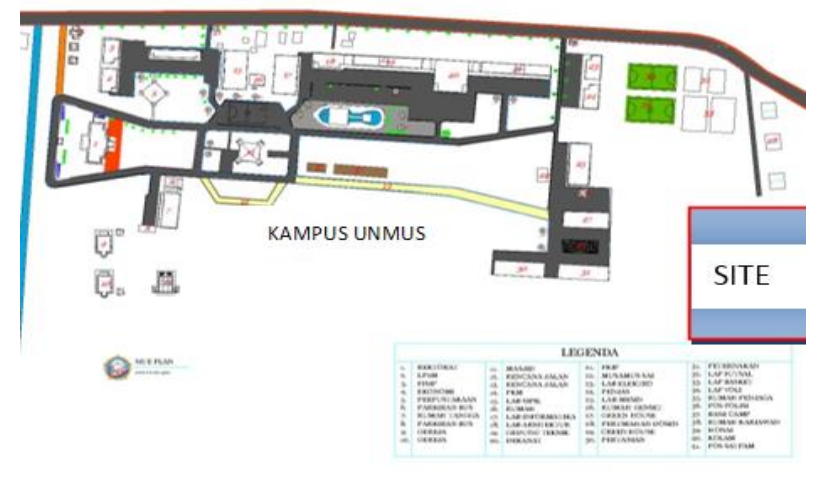

Gambar 2. Lokasi tapak

\subsection{Pencapaian}

Pencapaian ke dalam tapak dapat melalui jalan Kamizaun. Lokasi tapak berada di kawasan yang sedang berkembang, sehingga nantinya akan menimbulkan masalah kemacetan. Maka diperlukan perhatian terhadap desain pengaturan sirkulasi kendaraan dari/menuju tapak, sehingga tidak menimbulkan kemacetan pada jalan tersebut. 


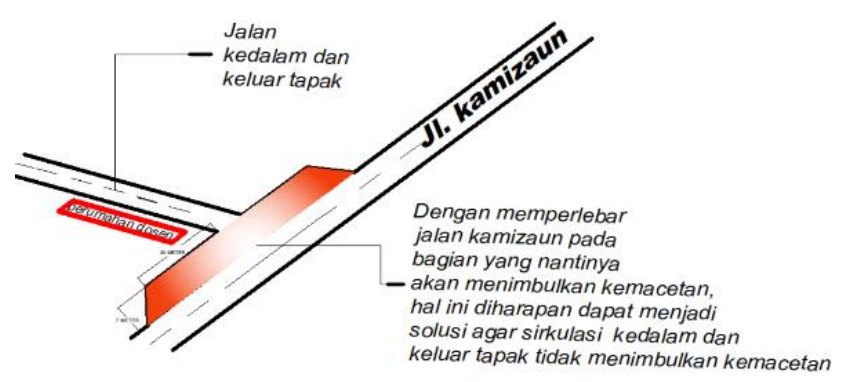

Gambar 3. Pencapaian ke tapak

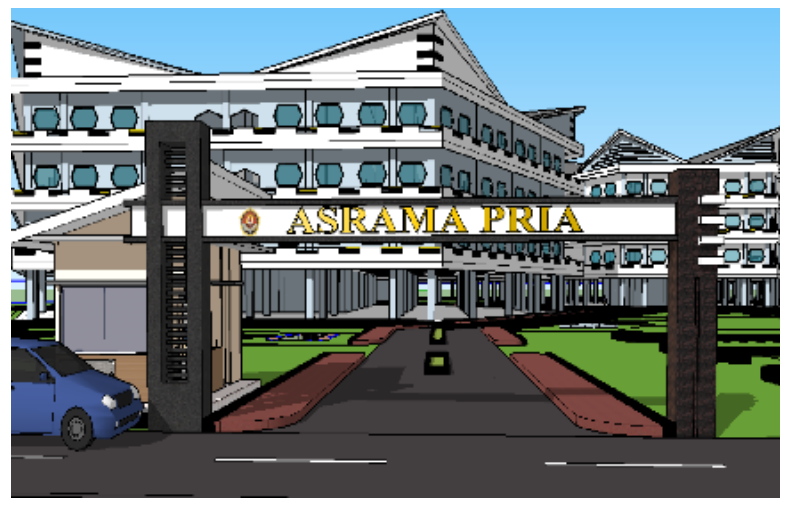

Gambar 4. Sirkulasi asrama pria

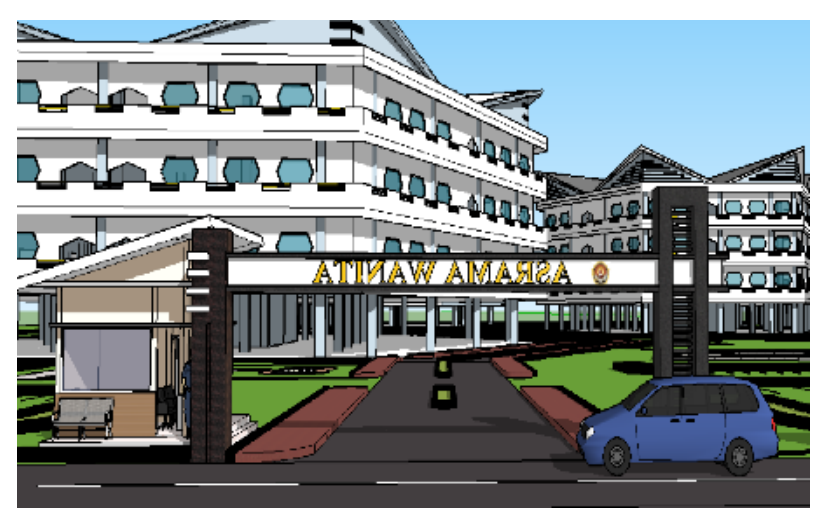

Gambar 5. Sirkulasi asrama wanita

\subsection{Sirkulasi Parkir}

Berdasarkan hasil analisis maka pola parkir yang tepat untuk diterapkan pada Asrama Mahasiswa yaitu pola parkir dengan sudut $90^{\circ}$ yang telah memenuhi kriteria sebagai berikut, Keluar masuk parkir mudah, Daerah/luar tempat parkir relatif lebih luas dan Kenyamanan sirkulasi.
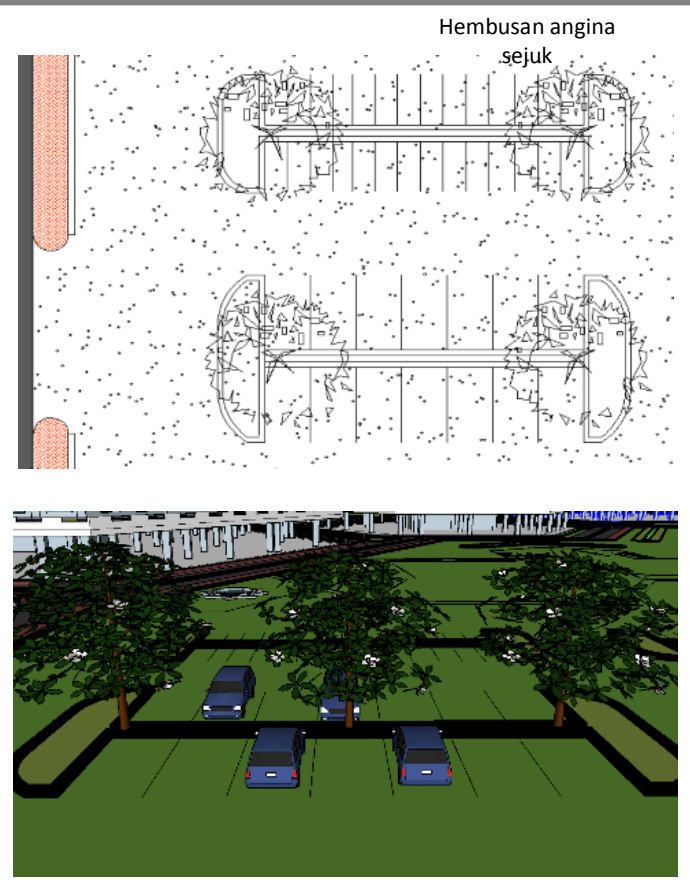

Gambar 6. Sirkulas Parkir

\subsection{Arah Angin}

Untuk mengatasi hembusan angin yang besar, maka perlu penanganan dengan memecah angina dengan penempatan bangunan-bangunan yang ada didalam tapak agar sebagian dapat masuk ke dalam bangunan untuk dimanfaatkan sebagai penghawaan alami.Selain dengan pemanfaatan penempatan bangunan, vegetasi adalah salah satu cara solusi dalam pemecah angin pada tapak.

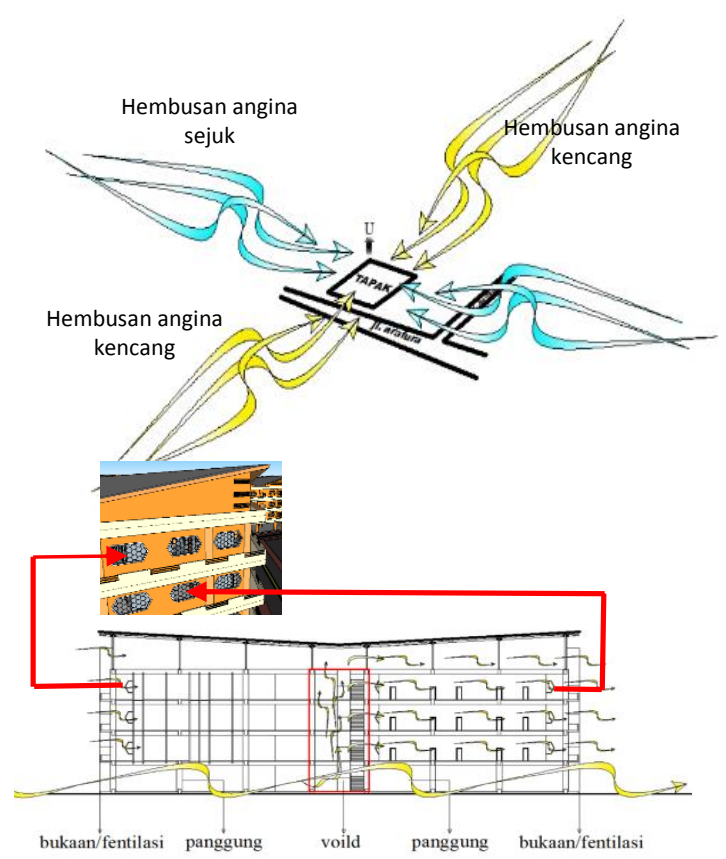

Gambar 7. Arah Angin 


\subsection{Orientasi Matahari}

Kondisi sekitar tapak yang merupakan lahan kosong membuat penyerapan sinar matahari langsung dari timur dan barat pada tapak dapat diolah dan dimanfaatkan dengan baik. Pemanfaatan cahaya matahari yang di maksimalkan pada seluruh bangunan terutama cahaya matahari dipagi hari hingga siang hari. Dalam mengurangi cahaya matahari pada sore hari yang berlebihan masuk pada ruangan-ruangan dalam bangunan yaitu dengan memberikan penghalang berupa secondry skinpada bangunan yang dapat menghalangi cahaya langsung dari cahaya matahari.

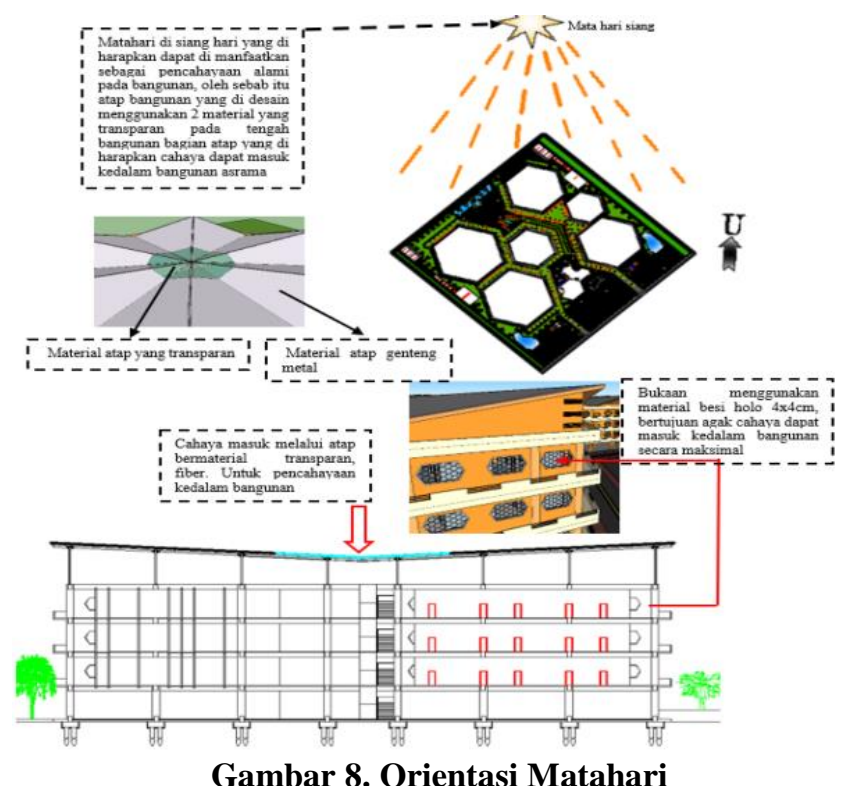

\subsection{Konsep Vegetasi}

Penerapan vegetasi berupa pemilihan jenis vegetasi yang tepat dan disesuaikan dengan fungsinya pada area tapak yang diharapkan dapat menjadi pengontrol terhadap kondisi tapak mengenai arah matahari, arah angin, dan kebisingan.
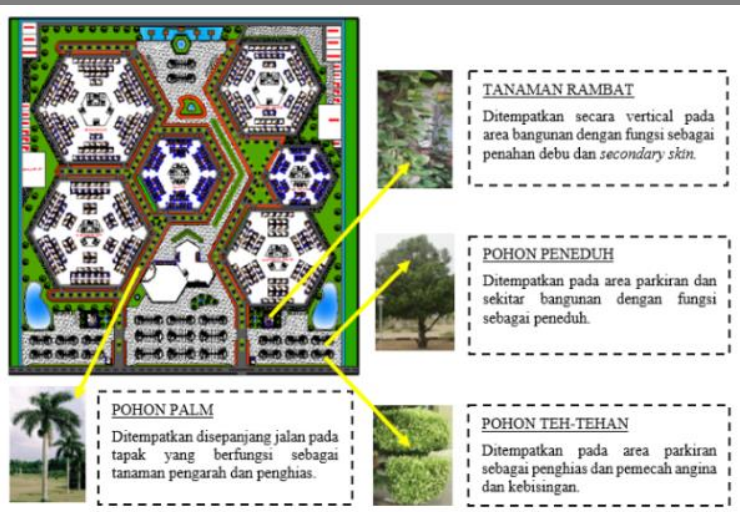

\section{Gambar 9.Konsep Vegetasi}

\subsection{Kebisingan}

Kondisi lalu lintas pada jalan Arafura dan jalan Kamizaun tergolong kepadatan lalu lintas yang cukup tinggi, dan hampir tidak ada penghalang yang dapat meredam tingkat kebisingan pada tapak. Faktor yang menyebabkan kebisingan bisa sampai ke tapak adalah permukaan tapak yang relatif lebih rendah dari jalan raya. Dalam mengantisipasi kebisingan tersebut adalah dengan menghalanginya masuk secara langsung ke dalam tapak dengan menggunakan vegetasi (tumbuhan/tanaman).

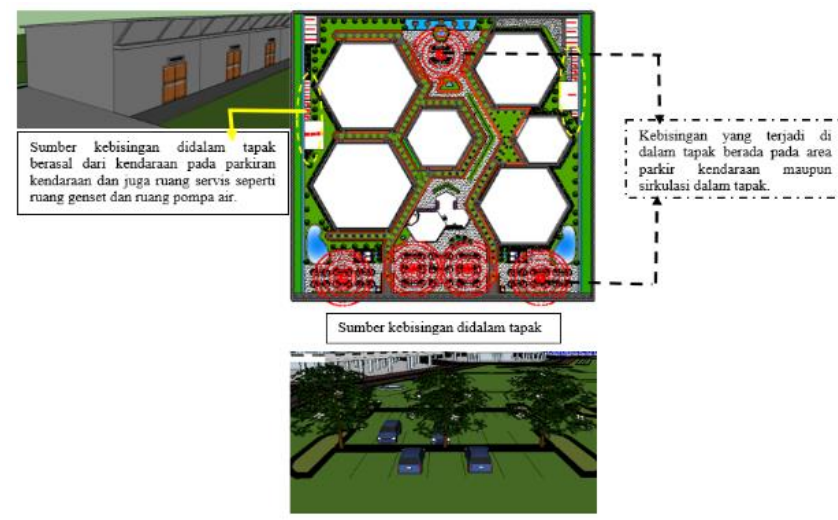

Gambar 10. Kebisingan

\subsection{Pendekatan Arsitektur}

Pendekatan arsitektur yang diterapkan pada asrama mahasiswa adalah pendekatan Green Arsitektur. Berdasarkan ciri bangunan green arsitektur adalah memiliki banyak bukaan seperti jendela-jendela yang besar dan tinggi. Berdasarkan hasil analisis gubahan masa untuk mendapatkan bentuk dasar bangunan yang tepat pada tapak yang dilihat dari segi bentuk dasar, filosofi bentuk dan pendekatan arsitektur. 


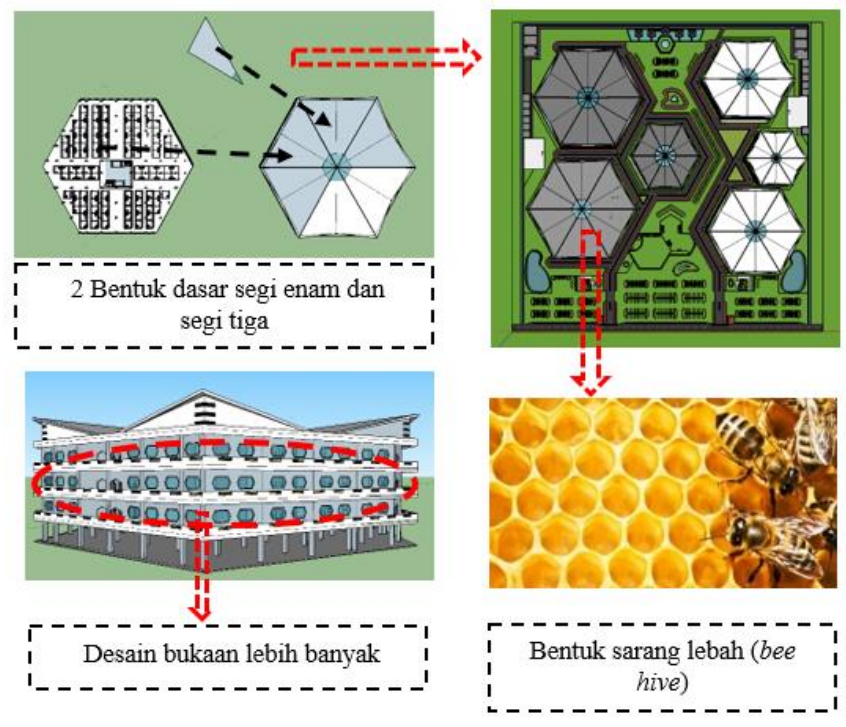

Gambar 11. Pendekatan Arsitektur

\subsection{Pola Tata Ruang}

Berdasarkan hasil analisis maka pola penataan ruang yang sesuai dengan dasar pertimbangan yaitu pengabungan antara pola cluster dan liniear, hal ini dikarenakan dengan penataan pola seperti ini maka hubungan/sirkulasi antar ruang menjadi lancar dan pada setiap ruang tetap mendapatkan penghawaan dan pencahayaan yang cukup.

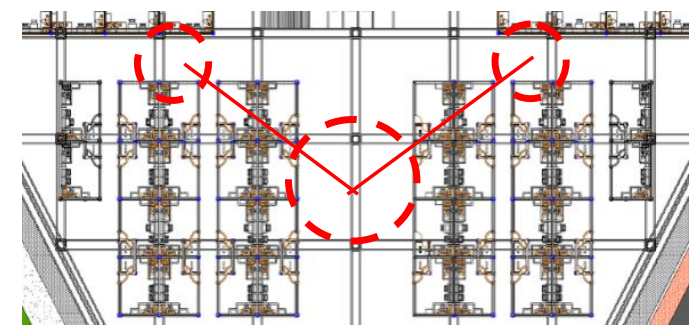

Gambar 12. Pola Tata Ruang

\subsection{Organisasi Ruang}

Organisasi ruang ditentukan untuk mendapatkan pola penataan ruang dalam bangunan. Berikut ini adalah organisasi ruang secara makro pada bangunan asrama mahasiswa.

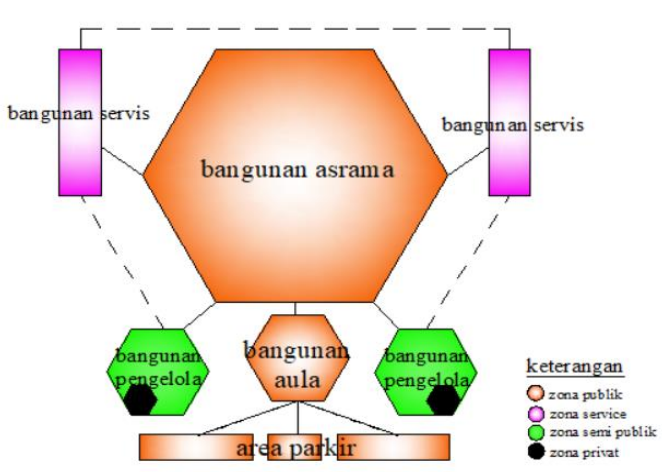

Gambar 13. Organisasi Ruang Makro

\subsection{Struktur Bangunan}

Adapun beberaapa struktur pada bangunan adalah sebagai berikut:

1. Sub Structure adalah struktur bawah bangunan atau pondasi di mana bangunan tersebut berdiri. Adapun beberapa struktur yang digunakan yaitu:

a. Pondasi tiang pancang mempunyai tegangan tekan yang besar, tidak terpengaruh oleh tinggi muka air tanah dan dapat tahan lebih lama dari pondasi lainnya. Tiang pancang yang digunakan pada perancangan ini yaitu tiang pancang beton dengan jenis precast reinfored concrete pile yaitu memiliki bentuk lingkaran.

b. Sistem pondasi menerus digunakan apabila lapisan tanah mempunyai daya dukung baik. Pondasi menerus diterapkan pada bangunan pos satpam, bangunan penjaga asrama, bangunan pengelola dan bangunan genset serta pompa air.
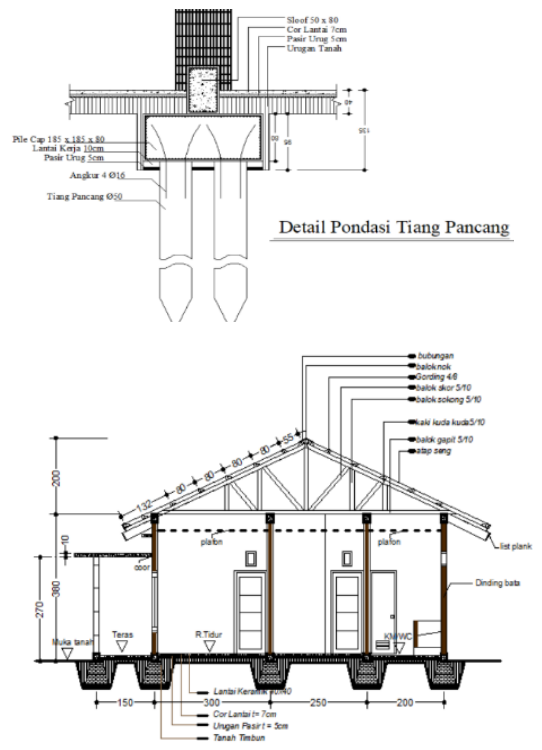

Gambar 14. Sub Structure 
2. Mid Structure adalah struktur bagian tengah bangunan yang terdiri atas, struktur kolom, balok dan dinding. Adapun struktur bagian tengah yang digunakan adalah:

a. Struktur kolom merupakan sebuah elemen yang menerima gaya aksial tekan dan gaya momen pada ujung-ujungnya.

b. Struktur balok merupakan bagian dari struktur yang berfungsi untuk menopang lantai diatasnya, balok juga berfungsi sebagai penyalur momen menuju kolom.

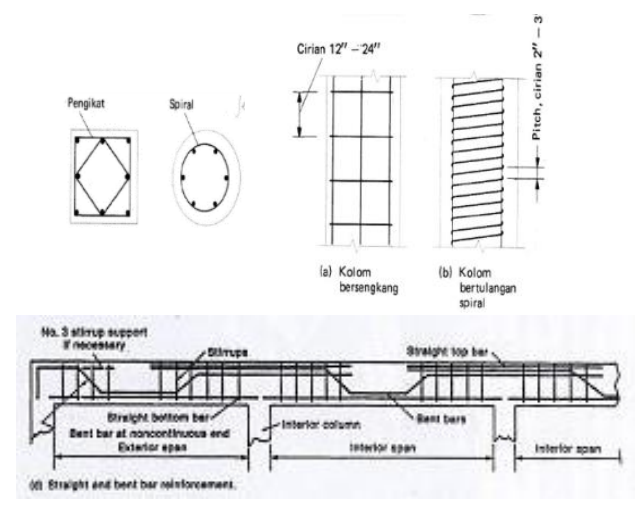

Gambar 15. Mid Structure

5. Upper structure yang digunakan pada bagian ini dapat berupa sistem konvensional untuk grid bangunan dengan bentang kecil dan sistem struktur advance untuk grid bangunan dengan bentang lebar. Struktur kolom merupakan sebuah elemen yang menerima gaya aksial tekan dan gaya momen pada ujung-ujungnya.
a. Struktur atap kayu
b. Struktur atap rangkabaja
c. Struktur atap beton

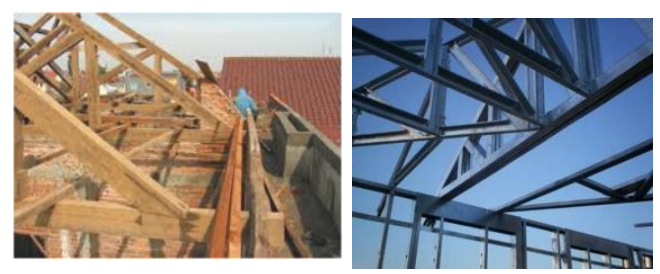

Gambar 16. Upper Structure

\subsection{Bahan Bangunan}

Dalam penggunaan bahan sebagai material dan finishing pada perancangan ini mengacu pada pendekatan arsitektur yaitu Green Architecture. 1. Material struktur
Pemilihan material struktur merupakan hal yang sangat penting karena berkaitan dengan vitalitas bangunan. Adapun jenis material yang bisa digunakan adalah beton, baja dan kayu

2. Material interior

Penampilan dalam bangunan dibuat sedemikian rupa sehingga pelaku kegiatan merasa nyaman, memberikan kesan menarik serta mewah dan juga terhadap akustik ruang sehingga pelaku kegiatan merasa betah berada dalam ruangan.

3. Material eksterior

Penampilan luar bangunan asrama selain mempengaruhi bentuk bangunan, juga dengan pengunaan material eksterior, sehingga dapat memberi kesan menarik sesuai dengan fungsi bangunan.

\subsection{Utilitas Air Bersih}

Air bersih dalam perancangan ini berasal dari PDAM dan sumur yang kemudian ditampung pada bak air. Setelah itu air dialirkan pada beberapa tandon air melalui pompa, untuk penyaluran selanjutnya dari tandon air dapat langsung di distribusikan pada unit-unit bangunan.

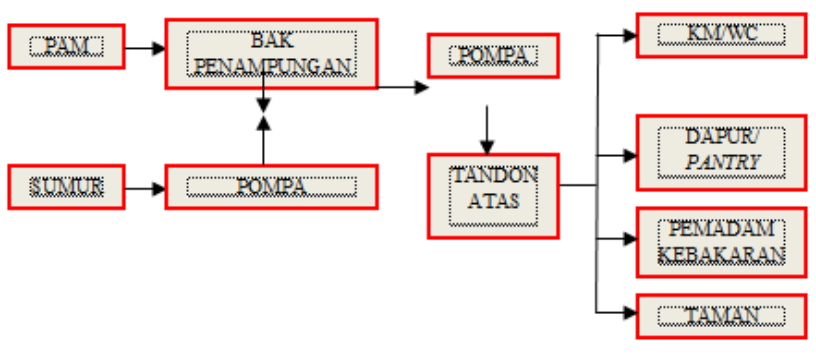

Diagram 1. Utilitas Air Bersih
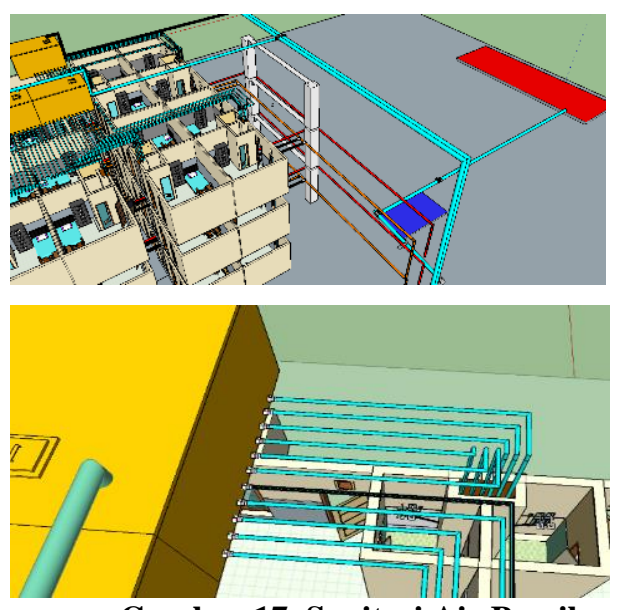

Gambar 17. Sanitasi Air Bersih 


\subsection{Utilitas Air Kotor}

Konsep penyaluran air kotor terutama limbah cair yang berasal dari pantry dan cafetaria adalah dengan menggunakan sistem grease trap yang berfungsi untuk menangkap lemak. Pengguanaan grease trap sangat baik dikarenakan untuk menghindari pencemaran pada saluran drainase perkotaan dan juga menghindari penunmpukan lemak pada saluran pipa pembuangan.

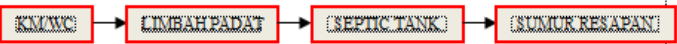

Diagram 2. Sistem Pembuangan limbah cair

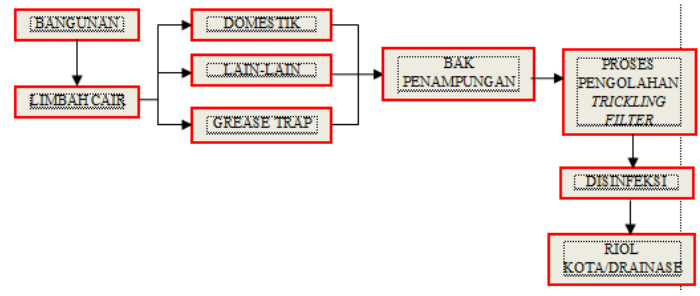

Diagram 3. Sistem Pembuangan limbah padat

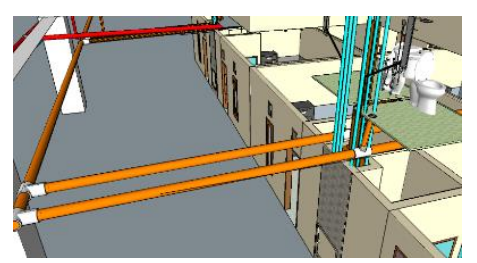

Gambar 18. Sanitasi Air Kotor

\subsection{Utilitas Air Hujan}

Pemanfaatan air hujan secara maksimal yang diharapkan dapat dimanfaatkan untuk kebutuhan sehari-hari dengan menampung air dibak penampungan air bersih, selebihnya dengan mengalirkan ke drainase tapak, drainase bangunan dan juga kolam-kolam yang diharapkan dapat mengalirkan dan menampung air hujan yang berlebihan.

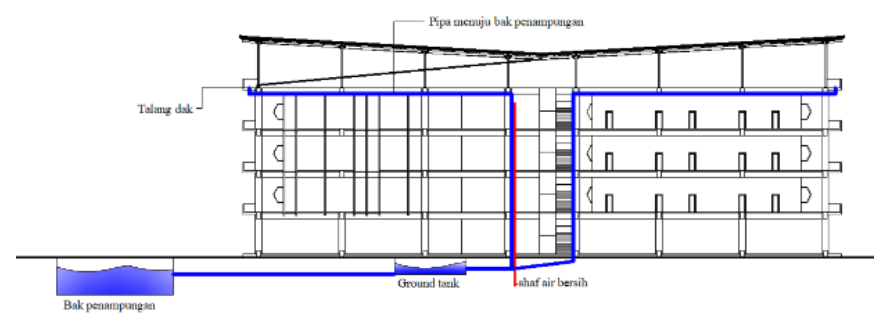

Gambar 19. Sanitasi Air Hujan

\subsection{Utilitas Air Tinja}

Air tinja atau kotoran manusia merupakan limbah padat yang perlu penanganan khusus untuk memberikan solusi pengolahannya, berikut adalah ilustrasi dari solusi desain pada asrama mahasiswa dalam penanganan limbah tinja.

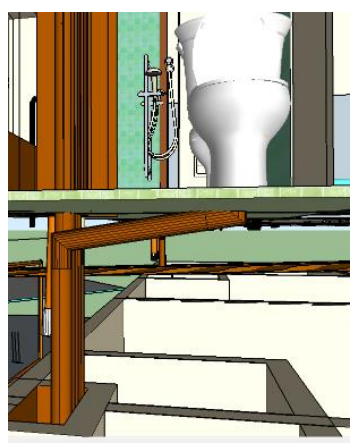

Gambar 20. Sanitasi Air Tinja

\subsection{Energi Listrik}

Energi listrik utama yang digunakan adalah berasal dari PLN, yang kemudian disalurkan ke panel utama dari bangunan dan dialirkan lagi ke panel listrik pada setiap bangunan. Untuk mengantisipasi pemadaman listrik oleh PLN, maka disiapkan genset sebagai cadangan listrik yang dilengkapi dengan automatic switch agar secara otomatis menghidupkan genset jika aliran utama listrik terjadi pemadaman.

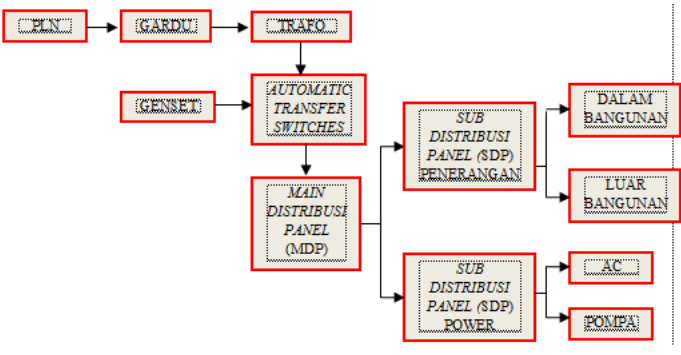

Diagram 4. Sistem Jaringan Listrik

\subsection{Sistem Keamanan}

Dalam perancangan ini, untuk menjaga keamanan bagi pengelola gedung, penyelenggara kegiatan dan pengunjung saat melakukan aktifitas dalam ruangan harus diberikan sistem pelayanan keselamatan yang baik.

1. Untuk mengatasi kebakaran yang terjadi, maka diperlukan alat-alat pemadam kebakaran yang mudah dijangkau dan mudah digunakan serta praktis. Alat-alat pemadam kebakaran 
diantaranyaSmoke detector, Fire alarm, Sprinkler, Hidrant, dan halon free.

2. Tangga Kebakaran difungsikan sebagai jalur sirkulasi vertikal untuk pengguna gedung jika terjadi bahaya kebakaran yang dapat mengakibatkan lift terkunci dan tidak dapat digunakan. Untuk mengetahui kebutuhan tangga kebakaran adalah dengan terlebih dahulu mengetahui jumlah kapasitas pengunjung dalam gedung. Jumlah penghuni bangunan pada perancangan ini adalah 3000 orang. Untuk setiap $60 \mathrm{~cm}$ lebar tangga melewatkan 30 orang per menit. Dan waktu pengosongan gedung dimana saat terjadi kebakaran adalah dalam waktu 5 menit. Maka lebar tangga minimum yang dibutuhkan adalah $12 \mathrm{~m}$.

3. Untuk mengantisipasi dan mengatasi tindak kriminal, maka sistem keamanan yang digunakan adalah dengan memasang alat CCTV. CCTV berfungsi sebagai alat perekam suatu kejadian atau aktifitas pada waktu dan tempat tertentu. Sistem kerja CCTV adalah dengan terlebih dahulu mengatur mengatur sistemnya, kemudian hasil perekaman adalah bergantung pada persediaan kapasitas pada media penyimpanan DVR (Digital Video Recorder).

4. Penangkal petir yang digunakan pada perancangan ini adalah penangkal petir flash vectron. Sistem ini aktif bekerja dengan sifat menarik petir untuk menyambar pada bagian kepala terminal. Area perlindungan system ini berupa bola dengan radius mencapai 150 meter dan radius ini akan mengecil sejalan dengan bertambahnya waktu. Untuk perancangan ini panjang denah pada bangunan adalah sekitar $200 \mathrm{~m}$ dan lebar 100m, maka dibutuhkan 2 penangkal petir jenis flesh vectron.

\subsection{Sampah}

Penanganan pengelolaan pada perancangan ini tidak dapat dilakukan hanya oleh bagian kebersihan. Pengelolaan sampah yang dillakukan diinternal sekitaran bangunan, kemudian diletakkan pada Tempat Pembuangan Sementara (TPS) di lokasi tapak. Sampah tersebut perlu diangkut ke tempat pembuangan akhir (TPA).

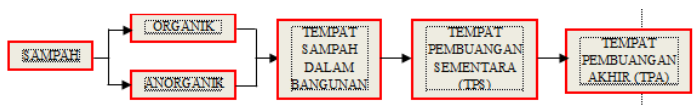

Diagram 5. Sistem Pembuangan Sampah

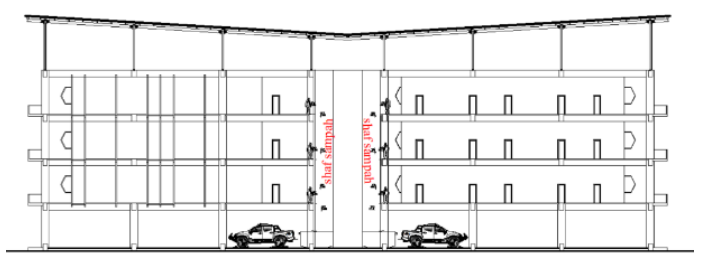

Gambar 21. Sistem Shaft sampah bangunan

\subsection{Hasil Perancangan}

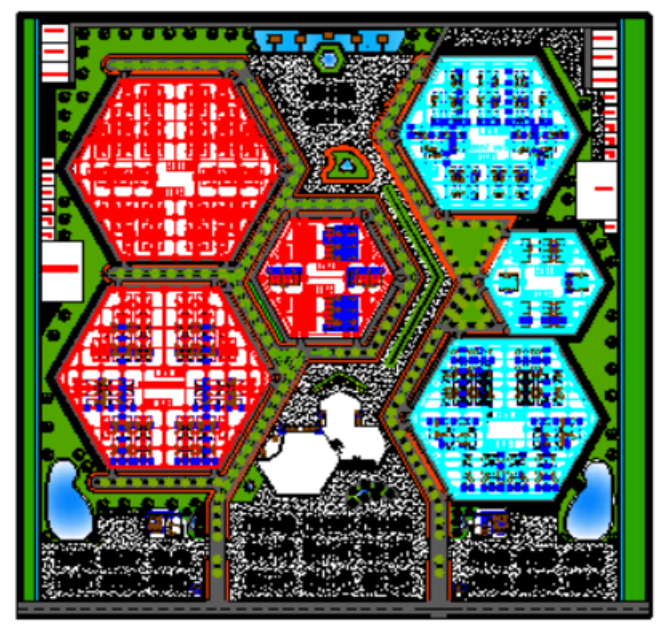

Gambar 22. Siteplan Asrama Mahasiswa

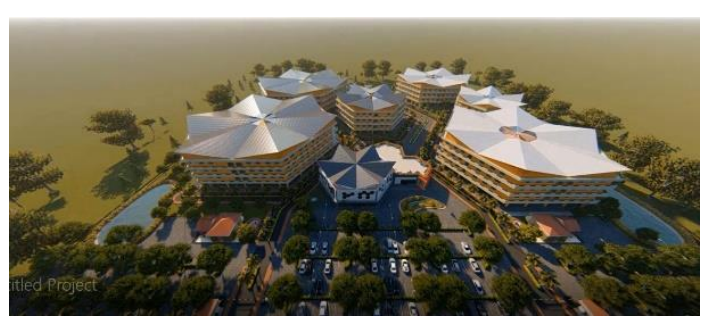

Gambar 23. 3D Siteplan

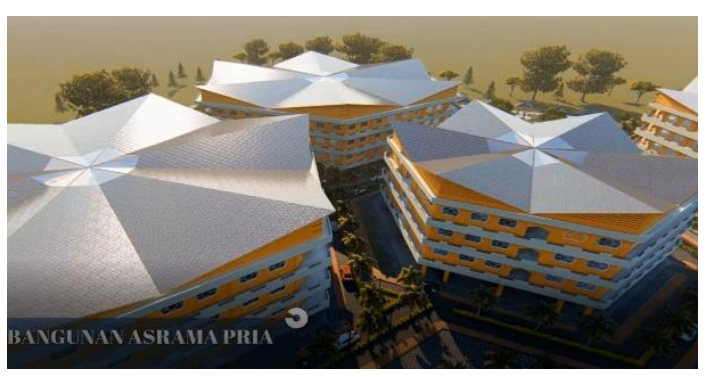

Gambar 24. 3D Asrama Pria 


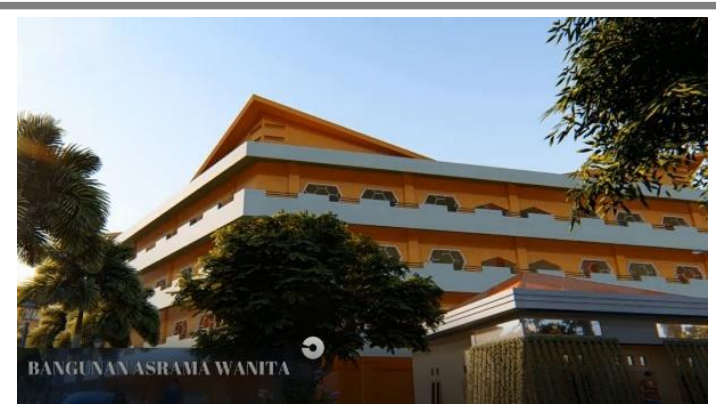

Gambar 25. 3D Asrama Wanita

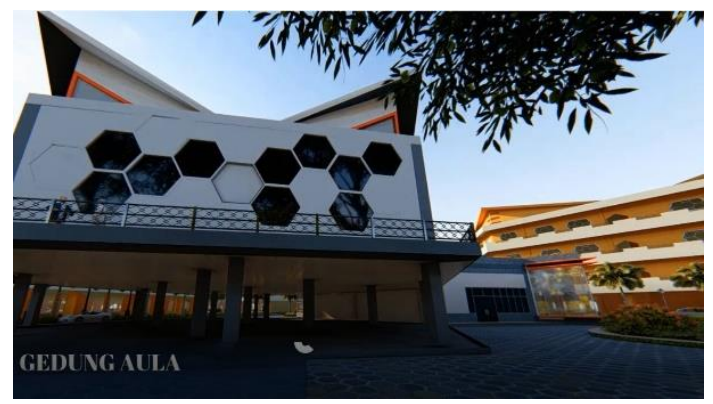

Gambar 26. 3D Gedung Aula

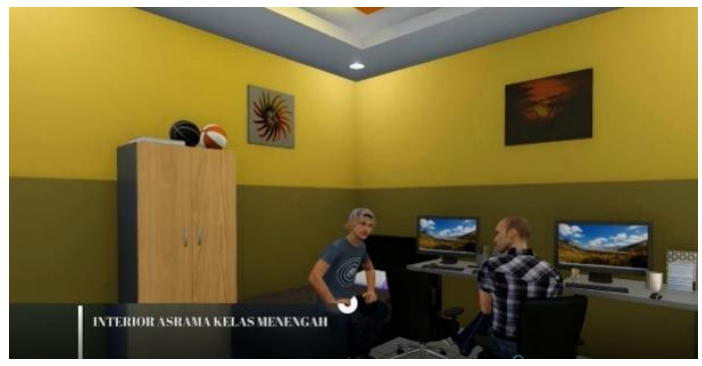

Gambar 27. Interior Design

\section{PENUTUP}

kesimpulan:

1. Tapak yang di rencanakan untuk membangun sebuah asrama mahasiswa berada dijalan Kamizaun dengan luasan tapak $90.000 \mathrm{~m}^{2}(9 \mathrm{Ha})$. Tapak yang di rencanakan sudah sesuai dengan criteria pemilihan lokasi site yakni sesuai dengan Rencana Detail Tata Ruang (RDTR) Kota Merauke, pencapain mudah dan kelengkapan utilitas kota.

2. Perencanaan dan perancangan asrama mahasiswa dengan menerapkan tema green architecture yaitu dengan menerapkan Tema perancangan "hive" yang berarti Lebah, banyak hal tentang lebah salah satunya adalah Apik dan Resik (bagus dan bersih). Maksud dari tema perancangan ini adalah penerapan dari karakter lebah yang mempunyai sifat apik dan resik, yang di harapkan dapat di terapkan pada perencanaan dan perancangan asrama mahasiswa yang apik dan resik, yang berarti bahwa perancangan asrama mahasiswa ini di harapkan mempunyai tampilan fisik yang apik (bagus) serta memiliki jaringan utilitas yang baik sehingga menciptakan rancangan yang terlihat resik (bersih).

3. Adapun unsur filosofi bentuk pada perancangan asrama mahasiswa ini yaitu: bee hive (sarang lebah). Alasan mengambil filosofi ini adalah kehebatan bentuk heksagon (segi enam) yang terdapat pada sarang lebah yang akan di terapkan pada perancangan asrama mahasiswa UNMUS.

\section{Referensi}

[1] Putu Dera Lesmana Prawibawa dan Happy Ratna Santosa 2015. "Konsep Arsitektur HijauSebagai Penerapan Hunian Susun di Kawasan Segi Empat Tunjungan Surabaya". Jurnal: JURNAL SAINS DAN SENI ITS Vol. 4, No.2,(2015) 2337-3520(2301928XPrint)DIKTI

[2] Hebel Bata. 2016. Kriteria Rumah dan Bangunan Tahan Gempa.

[3] JOSEPH De CHIARA and JOHN HANCOCK CALLENDER. 2001.Time Saver Standards for Building Types Second.

[4] Sugiyono,2016. Metode Penelitian Kuantitatif, Kualitatif, dan R\&D. Alfabeta Bandung. 